\title{
EKOLOGI PENAMAAN KELURAHAN DI KOTA MATARAM
}

\author{
Imam Subayil \\ Universitas Mataram \\ sdn29_mataram@yahoo.com
}

\begin{abstract}
Abstrak
Masalah utama yang dikaji pada penelitian ini adalah mengidentifikasi bentuk dan makna penamaan kelurahan di Kota Mataram. Pendekatan deskriptif merupakan pendekatan yang digunakan dalam penelitian ini. Pendekatan deskriptif digunakan untuk membuat deskripsi atau gambaran, lukisan secara sistematis, faktual dan akurat mengenai data, sifat-sifat serta hubungan fenomena-fenomena yang diteliti. Penelitian ini menggunakan metode kualitatif. Metode ini digunakan ketika menghimpun dan menganalisa data tentang nama kelurahan di kota Mataram yang penamaannya berdasarkan ekologi. Metode pengumpulan data yang digunakan adalah metode observasi, simak, cakap, wawancara, dan rekam. Teknik analisis data dilakukan dengan mengumpulkan nama-nama kelurahan di Kota Mataram yang penamaannya berdasarkan ekologi dan menganalisis bentuk dan makna penamaannya. Berdasarkan pengamatan dan analisis data mengenai lingkungan biotic dan abbiotik ditemukan bahwa masyarakat Mataram menamai entitas atau objek yang berupa tempat/institusi yakni kelurahan yang ada di sekeliling mereka berdasarkan hal-hal berikut, yakni (1) Penamaan Berdasarkan Persamaan Sifat/Tingkah Laku, (2) Penamaan Berdasarkan Tempat/lahan tumbuh, (3) Penamaan Berdasarkan Kondisi, (4) Penamaan Berdasarkan Jumlah, (5) Penamaan berdasarkan Penemu/Pemilik Pertama, (6) Penamaan Berdasarkan Proses, (7) Penamaan Berdasarkan Bentuk, (8) Penamaan Berdasarkan Jumlah, (9) Penamaan Berdasarkan Ciri Fisik, (10) Penamaan Berdasarkan Manfaat/Fungsi, (11) Penamaan Berdasarkan Sifat, dan (12) Penamaan berdasarkan Arah.
\end{abstract}

Kata kunci: Penamaan, Ekolinguistik, Bentuk, dan Makna

\begin{abstract}
The main issues that are examined in this study are to identify the shape and meaning of naming village in Mataram. Descriptive approach is the approach used in this study. Descriptive approach is used to make a description or illustration, systematic figure, factual and accurate information on the data, properties and relations of phenomena under study. This study uses a qualitative method. This method is used when collecting and analyzing data about the name of the village in Mataram which naming based ecology. Data collection method used is the method of observation, analyzing, proficient, interviews, and recording. Data analysis techniques performed by collecting the names of villages in Mataram which its name is based on ecology and analyze the shape and meaning of its name. Based on the observation and analysis of environmental data on biotic and abbiotik found that people in Mataram named entity or object in the form of places / institutions that villages that surround them based on the following matters, namely (1) Based on Equation Naming Personality / Behavior, (2) Naming Based on the place / land, (3) Naming based on conditions, (4) Naming Based on Number, (5) Naming based on inventor / First owner, (6) Naming Based on the Process, (7) Naming Based on The shape, (8) Naming based on the amount, (9) Naming based on Physical Characteristics, (10) Naming based on the Benefits / Function, (11) Naming based on its Characteristic, and (12) Naming based on the Direction.
\end{abstract}

\section{Keywords: Naming, Ecolinguistics, Forms, and Meaning}

\section{PENDAHULUAN}

Nama adalah simbol bagi setiap benda yang memilikinya. Tanpa nama, dapat dibayangkan bahwa suatu benda akan sangat sulit disebut apalagi untuk dikenal orang. Pemberian nama terhadap suatu daerah merupakan hal yang sangat penting karena daerah sangatlah luas cakupannya.

Beberapa daerah lahir namanya melalui fenomena alam, nama-nama tumbuhan dan hewan, serta nama-nama benda alam lainnya. Daerah-daerah di Indonesia yang 
penamaannya berhubungan dengan ekologi contohnya Surabaya, yang diambil namanya dari nama dua hewan yaitu seekor ikan hiu dan buaya. Demikian juga dengan nama -nama daerah kelurahan lain di Kota Mataram. Kota Mataram terbagi menjadi enam kecamatan dan lima puluh kelurahan.

Untuk mengetahui keberadaan ekologi sebagai dasar penamaan kelurahan tersebut, penulis menggunakan kajian ekolinguistik. Ekolinguistik yang merupakan perpaduan ilmu bahasa dengan lingkungan dipandang tepat untuk mengungkap fenomena di atas karena berdasarkan lingkungan itulah lahirnya sebuah bahasa dan dengan bahasa itulah lingkungan menjadi dikenal. Fenomena ini memberikan inspirasi untuk melihat bagaimana hubungan antara Bahasa dan lingkungan serta bagaimana fenomena linguistik kognitif ini bisa berkontribusi terhadap pengajaran dan pembelajaran bahasa.

Berdasarkan uraian di atas, maka penelitian ini berjudul "Ekologi Penamaan Kelurahan di Kota".

\section{KONSEP DAN KERANGKA TEORI}

\section{Konsep}

\section{Nama}

Dunia ini penuh dengan nama-nama yang diberikan oleh manusia. Manusia tidak hanya memberi nama, tetapi memberi makna pula. Bahkan dirinya pun diberi nama dan makna pula. Nama merupakan katakata yang menjadi label setiap makhluk benda, aktivitas, dan peristiwa di dunia ini.

Aristoteles (384-322 SM), murid Plato mengatakan bahwa pemberian nama adalah soal perjanjian (bukan berarti dahulu ada sidang nama untuk sesuatu yang diberi nama). Nama biasanya dari seseorang (ahli, penulis, pengarang, pemimpin negara atau masyarakat baik melalui media masa elektronika, atau majalah dan Koran). Misalnya, di dalam fisika kita kenal hukum Boyle dan Archimides. Dalam permainan kita kenal sepak bola, teis meja, tenis, dan sebagainya. Nama sesuatu kadang-kadang dapat diusut asal-usulnya. Misalnya nama tempat di Indonesia, antara lain Banyuwangi, Sunda Kalapa, Pandeglang, dan sebagainya

\section{Ekolinguistik}

Ekologi adalah ilmu yang mempelajari tentang hubungan timbal balik antara makhluk hidup dengan lingkungannya. Haugen lebih memilih istilah ekologi bahasa (ecology of language) dari istilah lain yang bertalian dengan kajian ini. Hal tersebut dikarena istilah ekologi bahasa memiliki cakupan yang luas di dalamnya, yang mana para pakar bahasa dapat bekerjasama dengan pelbagai jenis ilmu sosial lainnya dalam memahami interaksi antar bahasa dan lingkungan. (Haugen dalam Mülhäusler, 2001:57).

\section{Teori}

\section{Cara Pemberian Nama}

Sibarani (2004:114-118) membagi tiga makna nama dalam antropolinguistik yaitu: makna nama pengharapan futuratif, makna 
nama pengharapan situasional, dan makna nama kenangan.

\section{1) Makna Nama Pengharapan Futuratif}

Makna nama pengharapan futuratif adalah makna nama yang mengandung pengharapan agar kehidupan pemilik nama seperti makna namanya (2004: 116). Selanjutnya, Sibarani mengemukakan makna nama pengharapan futuratif banyak terdapat pada nama orang, nama usaha dan nama tempat. Hal ini, mengacu pada makna nama diri pemilik nama yang mengandung pengharapan. Contoh makna nama pengharapan futuratif pada nama-nama orang dalam bahasa Batak Toba adalah “Andar" yang artinya jelas. Makna pengharapan futuratif dari nama tersebut adalah semoga menjadi orang yang berterus terang.

\section{2) Makna Nama Pengharapan}

\section{Situasional}

Makna nama pengharapan situasional adalah makna nama pengharapan yang mengandung harapan pada situasi pemberian nama (2004:115). Selanjutnya, Sibarani mengemukakan makna nama pengharapan situasional ini diberikan sesuai dengan nama yang mengacu pada situasi pada saat itu. Pada makna nama pengharapan situasional, pemaknaan dikaitkan dengan nilai-nilai budaya atau suatu kepercayaan bagi pemilik nama terhadap suatu hal yang dikaitkan dengan situasi dan kondisi. Makna nama situasional ini banyak ditemukan di tengah masyarakat, dan makna pengharapan situasional mengandung harapan sesuai dengan situasi. Contoh makna pengharapan situasional pada nama-nama orang dalam bahasa Batak Toba adalah "Benget" yang artinya tawakal/ sabar. Makna dari nama tersebut adalah keadaan keluarganya saat itu yang kurang sejahtera sehingga diharapkan menjadi orang yang bertawakal/ bersabar.

\section{3) Makna Nama Kenangan}

Makna nama kenangan adalah makna nama yang mengandung kenangan (2004:118). Selanjutnya Sibarani mengemukakan makna nama kenangan ini diberikan sesuai dengan kenangan yang dialami pemberi nama. Contoh makna kenaangan pada nama-nama orang dalam bahasa Batak Toba adalah "Mardeka" yang artinya merdeka. Makna dari nama tersebut adalah kenangan bahwa seseorang lahir pada hari kemerdekaan.

Cara pemberian nama beraneka ragam di antaranya berasal dari peniruan bunyi, penyebutan bagian, penyebutan sifat khas, penemu dan pembuat, tempat asal, bahan, keserupaan, pemendekan, dan penamaan baru.

\section{a) Peniruan Bunyi/ Onomatope}

Sejumlah kata terbentuk berdasarkan bunyi dari benda tersebut atau suara yang ditimbulkan oleh benda tersebut. Misalnya, binatang sejenis reptil kecil yang melata di dinding disebut cecak karena bunyinya 
"cak, cak, cak".

\section{b) Penyebutan Bagian}

Penamaan suatu benda atau konsep berdasarkan bagian dari benda itu biasanya berdasarkan ciri yang sudah diketahui umum pada benda itu. Misalnya, tidak ada Soekarno-Hattanya berarti tidak ada uang seratus ribunya, sebab uang kertas sekarang bergambar Soekarno-Hatta (lembar seratus ribu).

\section{c) Penyebutan Sifat Khas}

Penanaman sesuatu benda berdasarkan sifat khas yang sangat menonjol pada benda itu. Contohnya anak yang kulitnya hitam disebut si hitam.

\section{d) Penemu dan Pembuat}

Banyak nama benda dalam kosakata bahasa Indonesia yang dibuat berdasarkan nama penemunya yaitu mujahir atau mujair, sejenis ikan laut tawar yang mula-mula ditemukan dan diternakan oleh seorang yang bernama mujair di Kediri, Jawa Timur.

Nama orang atau nama pabrik dan merek dagang kemudian menjadi nama benda hasil produksi seperti aspirin obat sakit kepala, miwon bumbu masak dan sebagainya.

\section{e) Tempat Asal}

Sejumlah nama benda dapat ditelusuri berasal dari nama tempat asal benda tersebut. Misalnya kata magnet berasal dari na- ma tempat Magnesia. Kata kenari, yaitu nama sejenis burung, berasal dari nama Pulau Kenari di Afrika, dan sebagainya.

\section{f) Bahan}

Ada sejumlah benda yang namanya diambil dari nama pokok benda itu. Misalnya, karung yang dibuat dari goni. Jadi, kalau dikatakan membeli beras dua goni, maksudnya membeli beras dua karung.

\section{g) Keserupaan}

Dalam praktik berbahasa, banyak kata yang digunakan secara metaforis. Misalnya kata kaki ada frase kaki meja, kaki gunung, dan kaki kursi. Di sini kata kaki mempunyai kesamaan makna dengan salah satu ciri makna dari kata kaki itu yaitu, "alat penopang berdirinya tubuh" pada frase kaki meja dan kaki kursi, dan ciri "terletak pada bagian bawah" pada frase kaki gunung.

\section{h) Pemendekan}

Kata-kata dalam bahasa Indonesia yang terbentuk sebagai hasil penggabungan unsur -unsur huruf awal atau suku kata dari beberapa kata yang digabungkan menjadi satu. Misalnya, ABRI yang berasal dari Angkatan Bersenjata Republik Indonesia.

\section{i) Penamaan Baru}

Penamaan baru ialah kata atau istilah baru yang dibentuk untuk menggantikan kata atau istilah yang sudah ada diganti dengan kata-kata baru atau sebutan baru, ini terjadi karena kata-kata lama dianggap ku- 
rang tepat, tidak rasional, kurang ilmiah dan kurang halus. Contoh penamaan baru atau penggantian kata adalah kata turisme menjadi pariwisata, piknik menjadi darma wisata, dan onderdil menjadi suku cadang.

\section{Ekolinguistik}

Ekologi bahasa sebagai suatu kajian ilmu yang membahas tentang interaksi antara bahasa dengan lingkungannya, sehingga sangat ditentukan oleh orang-orang yang mempelajarinya, menggunakannya, dan mengirimkannya kepada orang lain.

\section{PEMBAHSAAN}

\section{1) Bentuk-bentuk Leksikon Penamaan Kelurahan di Kota Mataram}

Penamaan kelurahan di Mataram didasarkan atas dua aspek yakni lingkungan biotik dan abiotik.

\section{a) Cara Penamaan Lingkungan Biotik}

Berdasarkan pengamatan dan analisis data mengenai lingkungan biotik ditemukan bahwa masyarakat Mataram menamai entitas atau objek yang berupa tempat/institusi yakni kelurahan yang ada di sekeliling mereka berdasarkan hal-hal berikut.

\section{i) Penamaan Berdasarkan Persamaan Sifat/Tingkah Laku}

Penamaan didasarkan atas persamaan sifat/tingkah laku termasuk leksikon Dasan Cermen, yang merupakan suatu dusun kecil di mana banyak masyarakatnya melakukan kegiatan pengolahan buah cermen (buah cermai). Monjok berasal dari kata monjlok yang artinya jatuh/ dijatuhkan. Monjok awalnya merupakan suatu wilayah kecil. Penduduknya berasal dari punggawa kerajaan di Lombok yang dibuang dari kerajaan karena fitnah (untuk dijatuhkan kekuasaannya). Nama Kelurahan Monjok Barat dan Monjok Timur merupakan Monjok yang dibagi sesuai letaknya. Kebunsari, dinamakan demikian agar bisa menarik perhatian/ tempat yang banyak sarinya/ terlihat seperti kebun tempat adanya berbagai bunga. Pagutan berasal dari kata "pangutan" yang artinya contoh yang baik. Nama Kelurahan Pagutan Barat dan Pagutan Timur merupakan Pagutan yang dibagi sesuai letaknya. Abian tubuh berasal dari kata "abian" yang artinya kebun dan "tubuh" yang artinya "tumbuh atau hidup". Dasan Agung, desa yang kecil tapi sering dikunjungi oleh orang-orang besar seperti raja Bali. Dasan Agung Baru merupakan nama yang diperoleh dari hasil pemekaran Dasan Agung.

\section{ii) Penamaan Berdasarkan Tempat/lahan tumbuh}

Penamaan ini sesuai dengan nama Pejeruk yang merupakan lahan dari raja Karang asem kepada penduduk di daerah tersebut untuk menanami bibit jeruk. Babakan yang berasal dari kata bakakan yang artinya sumber makanan yang berlimpah. Bertais, berasal dari kata "bare" yang artinya kandang dan "tais" berarti kering. Bertais yang merupakan pusat ternak di mana kan- 
dangnya selalu kering walaupun hujan deras. Selagalas yang diambil dari kata selageles. Kata "selageles" berasal dari kata sela yang artinya jalan yang sangat sempit dan "geles" yang artinya kecil. Dulunya merupakan sebuah hutan lebat dengan jalan sempit.

\section{iii)Penamaan Berdasarkan Kondisi}

Nama kelurahan yang penamaannya didasarkan atas kondisi, yakni kelurahan Pajarakan Karya. Pada awalnya, Pejarakan Karya bernama Pejarakan. Kata "Pejarakan" diambil dari peristiwa tiga orang saudara dari kerajaan Pejanggik yang tinggal di Sesela, Pejarakan, dan Dasan Agung. Oleh karena itu, daerah yang berada di tengahlah sebagai jarak, yang kemudian dinamakan Pejarakan.

\section{iv)Penamaan Berdasarkan Jumlah (kelompok)}

Penamaan kelurahan di Mataram juga ditunjang berdasarkan jumlah, seperti yang terlihat pada penamaan kelurahan Banjar yang merupakan sekelompok pendatang dari suku Banjar. Sapta Marga, maksudnya tujuh butir yang harus ditaati prajurit TNI. Cakranegara yang berasal dari dua kata "cakra" artinya lingkaran atau bundaran dan "negara" artinya kota, hunian, negeri atau kekuasaan.

\section{v) Penamaan Berdasarkan Manfaat/ Fungsi}

Ada sejumlah kelurahan yang dinamai berdasarkan manfaat/ fungsi yang diembannya terutama bagi kehidupan manusia. Contohnya Ampenan, berasal dari kata "amben" yang berarti tempat yang berfungsi atau bermantfaat untuk singgah. Nama Kelurahan Ampenan Tengah, Ampenan Selatan, Ampenan Utara merupakan Ampenan yang dibagi sesuai letaknya. Rembiga, diambil dari nama "remiga (dibaca remige)", nama pohon yang banyak tumbuh di daerah tersebut. Nama pohon rembiga secara keindonesiaan ialah pohon Widuri (dalam bahasa latin, Calotropis gigantean Dryand). Kegunaan kulit pohon, akar, daun, bunga dan getah rembiga untuk gigi rusak, radang anak telinga, radang lambung, kejang jantung, kudis, dan campak. Selain itu, ada Punia yang artinya tata cara hidup tenteram, penuh dengan tali persaudaraan yang tinggi. Kekalik Jaya, Kekalik berasal dari nama Kekaleq, nama gadis yang diasuh baloq Menah. Banyak orang datang ke sana mencari Kekaleq. Tujuan mereka adalah untuk melamarnya.

\section{vi)Penamaan berdasarkan Penemu/ Pemilik Pertama}

Penamaan berdasarkan Penemu/ Pemilik Pertama yakni Mataram yang penamaannya diberikan untuk mengenang bahwa daerah tersebut/ pulau Lombok pernah didatangi orang-orang dari kerajaan Mataram (dari pulau Jawa). Nama Mataram Barat dan Mataram Timur merupakan mataram berdasarkan letak wilayahnya, dan Gomong, 
diambil nama panggilan orang yaitu Gemong. Kelurahan itu diharapkan warganya suka kerja keras seperti Gemong.

\section{b) Cara Penamaan Lingkungan Abiotik}

Berdasarkan pengamatan dan analisis data mengenai lingkungan abiotic ditemukan bahwa masyarakat Mataram menamai entitas atau objek yang berupa tempat/institusi yakni kelurahan yang ada di sekeliling mereka berdasarkan hal-hal berikut.

\section{i) Penamaan Berdasarkan Proses}

Penamaan ini sesuai dengan penamaan kelurahan Pagesangan. Pagesangan berasal dari kata pegesengan yang artinya pembakaran mayat. Nama Kelurahan Pagesangan Barat dan Pagesangan Timur merupakan Pagesangan yang dibagi sesuai letaknya.

\section{ii) Penamaan Berdasarkan Persamaan Sifat/Tingkah Laku}

Cara penamaan berdasarkan persamaan sifat entitas terdapat pada penamaan Tamansari. Nama tersebut (Taman Sari) diberikan agar dijadikan sebagai tempat yang nayaman. Cilinaya yang merupakan nama seorang putri raja dari kerajaan Daha. Warga yang memberi nama daerah cilinaya tersebut mengharapkan agar daerah/ kelurahan itu memiliki penduduk yang cerdas, baik hati seperti Putri Cilinaya. Cakranegara yang berasal dari dua kata "cakra" artinya lingkaran atau bundaran dan "negara" artinya kota, hunian, negeri atau kekuasaan. Sayang-sayang merupakan tempat seorang prajurit biasa yang diberikan hak istimewa oleh raja Karang Asem. Pejanggik penamaannya sebagai harapan kelurahan itu kuat seperti kerajaan Penjanggiq. Mandalika diambil dari namaseorang puteri Negeri Tonjang Beru bernama Putri Mandalika. Puteri yang anggun dan cantik, terkenal ramah dan sopan. Tutur bahasanya lembut. Turida berasal dari kata "aturinde" yang artinya cara pembagian yang benar. Pada awalnya, Turida merupakan sebuah gubuk dengan penduduk di bawah garis kemiskinan dengan tidak memiliki bahan makanan. Jadi, penduduknya banyak diberikan bahan makanan oleh rakyat Babakan. Tanjung Karang, dinamakan seperti itu karena daerahnya merupakan tanjung dan diharapkan bisa permai.

\section{iii)Penamaan Berdasarkan Bentuk}

Ada beberapa kelurahan di Mataram yang dinamai berdasarkan kemiripan bentuk, di antaranya Doyan Peken, berasal dari dua kata, yaitu "doyan/ dayan" yang artinya utara dan "peken" yang artinya pasar. Karang Taliwang dinamakan demikian untuk mengenang daearah orang/ nenek moyang yang tinggal pada derah tersebut yakni Taliwang (Pulau Sumbawa, NTB) dan Mayura yang artinya burung Merak.

\section{iv)Penamaan Berdasarkan Ciri Fisik}

Beragam nama dan leksikon muncul karena keberagaman penamaan berdasarkan ciri fisik. Terdapat satu nama kelurahan 
yang penamaannya didasarkan atas cirri fisik yakni Karang Pule merupakan gubuk yang dikelilingi oleh pohon-pohon pule.

\section{v) Penamaan Berdasarkan Sifat}

Hal ini dapat dilihat pada nama Tamansari, Cilinaya, Cakranegara, Sayangsayang, Pejanggik, Mandalika, Turida, Tanjung Karang, dan Karang Baru.

\section{vi) Penamaan berdasarkan Arah}

Terdapat satu nama kelurahan yang penamaannya didasarkan atas arah adalah leksikon Bintaro awalnya menunjukkan arah di pinggir pantai kawasan Bintaro Kecamatan Ampenan di mana tersebut terdapat pohon bintaro.

Secara keseluruhan cara penamaan kelurahan dapat ditrangkum dan ditabulasakin dengan Tabel 4.1 berikut

Tabel 4.1

Cara Penamaan Kelurahan Leksikon Lingkungan Alam

\begin{tabular}{|c|c|c|c|c|c|c|c|c|c|c|c|c|}
\hline \multirow[t]{2}{*}{ Leksikon } & \multicolumn{12}{|c|}{ Cara Penamaan Kelurahan } \\
\hline & 1 & 2 & 3 & 4 & 5 & 6 & 7 & 8 & 9 & 10 & 11 & 12 \\
\hline Ampenan & & & & & & & & & & $\sqrt{ }$ & & \\
\hline Pejeruk & & $\sqrt{ }$ & & & & & & & & & & \\
\hline Banjar & & & & & & & & $\sqrt{1}$ & & & & \\
\hline Bintaro & & & & & & & & & & & & $\sqrt{ }$ \\
\hline Doyan Peken & & & & & & & $\sqrt{ }$ & & & & & \\
\hline Kebunsari & $\sqrt{ }$ & & & & & & & & & & & \\
\hline Pajarakan Karya & & & $\sqrt{ }$ & & & & & & & & & \\
\hline Tamansari & & & & & & & & & & & $\sqrt{ }$ & \\
\hline Cilinaya & & & & & & & & & & & $\sqrt{ }$ & \\
\hline Karang Taliwang & & & & & & & $\sqrt{ }$ & & & & & \\
\hline Mayura & & & & & & & $\sqrt{ }$ & & & & & \\
\hline Sapta Marga & & & & & & & & $\sqrt{ }$ & & & & \\
\hline Cakranegara & & & & & & & & $\sqrt{ }$ & & & $\sqrt{ }$ & \\
\hline Sayang-sayang & & & & & & & & & & & $\sqrt{ }$ & \\
\hline Pagutan & $\sqrt{ }$ & & & & & & & & & & & \\
\hline Mataram & & & & & +1 & & & & & & & \\
\hline Pagesangan & & & & & & $\sqrt{ }$ & & & & & & \\
\hline Pagutan & $\sqrt{ }$ & & & & & & & & & & & \\
\hline Pejanggik & & & & & & & & & & & $\sqrt{ }$ & \\
\hline Punia & & & & & & & & & & $\sqrt{ }$ & & \\
\hline Dasan Cermen & $\sqrt{ }$ & & & & & & & & & & & \\
\hline Babakan & & $\sqrt{ }$ & & & & & & & & & & \\
\hline Bertais & & $\sqrt{ }$ & & & & & & & & & & \\
\hline Abian Tubuh Baru & $\sqrt{ }$ & & & & & & & & & & & \\
\hline Mandalika & & & & & & & & & & & $\sqrt{ }$ & \\
\hline Selagalas & & $\sqrt{ }$ & & & & & & & & & & \\
\hline Turida & & & & & & & & & & & $\sqrt{ }$ & \\
\hline Tanjung Karang & & & & & & & & & & & $\sqrt{ }$ & \\
\hline Jempong Baru & & & & & & & & & & & & \\
\hline Karang Pule & & & & & & & & & $\sqrt{ }$ & & & \\
\hline Kekalik Jaya & & & & & & & & & & $\sqrt{ }$ & & \\
\hline Tanjung Karang Permai & & & & & & & & $\sqrt{ }$ & & & & \\
\hline Monjok & $\sqrt{ }$ & & & & & & & & & & & \\
\hline Karang Baru & & & & & & & & & & & $\sqrt{ }$ & \\
\hline Rembiga & & & & & & & & & & $\sqrt{ }$ & & \\
\hline Dasan Agung & $\sqrt{ }$ & & & & & & & & & & & \\
\hline Dasan Agung Baru & $\sqrt{ }$ & & & & & & & & & & & \\
\hline Gomong & & & & & ] & & & & & & & \\
\hline
\end{tabular}




\section{Keterangan :}

1) Penamaan Berdasarkan Persamaan Sifat/ Tingkah Laku

2) Penamaan Berdasarkan Tempat/lahan tumbuh

3) Penamaan Berdasarkan Kondisi

4) Penamaan Berdasarkan Jumlah

5) Penamaan berdasarkan Penemu/Pemilik Pertama

6) Penamaan Berdasarkan Proses

7) Penamaan Berdasarkan Bentuk

8) Penamaan Berdasarkan Jumlah

9) Penamaan Berdasarkan Ciri Fisik

10)Penamaan Berdasarkan Manfaat/Fungsi

11)Penamaan Berdasarkan Sifat

12)Penamaan berdasarkan Arah

\section{SIMPULAN}

Berdasarkan pengamatan dan analisis data mengenai lingkungan biotic dan abbiotik ditemukan bahwa masyarakat Mataram menamai entitas atau objek yang berupa tempat/institusi yakni kelurahan yang ada di sekeliling mereka berdasarkan hal-hal berikut, yakni (1) Penamaan Berdasarkan Persamaan Sifat/Tingkah Laku, (2) Penamaan Berdasarkan Tempat/lahan tumbuh, (3) Penamaan Berdasarkan Kondisi, (4) Penamaan Berdasarkan Jumlah, (5) Penamaan berdasarkan Penemu/Pemilik Pertama, (6) Penamaan Berdasarkan Proses, (7) Penamaan Berdasarkan Bentuk, (8) Penamaan Berdasarkan Jumlah, (9) Penamaan Berdasarkan Ciri Fisik, (10) Penamaan Berdasarkan Manfaat/Fungsi, (11) Penamaan Berdasarkan Sifat, dan (12) Penamaan Berdasarkan Arah.

\section{UCAPAN TERIMA KASIH}

Penulis mengucapkan terima kasih kepada mitra bestari atas kritikan dan masukan yang membangun untuk perbaikan artikel ini.

\section{DAFTAR PUSTAKA}

Alwasilah, Chaedar. 2011. Linguistik Suatu Pengantar. Bandung: ANGKASA.

Alwi, Hasan Dkk. 2010. Tata Bahasa Baku Bahasa Indonesia. Jakarata: Balai Pustaka

Aminuddin. 2011. Semantik Pengantar Studi Tentang Makna. Bandung: Sinar Baru Algensindo.

Anwar, Khaidar. 1995. Beberapa Aspek SosioKultural Masalah Bahasa. Yogyakarta: Gadjah Mada University press.

Ba'dulu, Abdul Muis. 2005. Morfosintaksis. Jakarta: PT RINEKA CIPTA

Chaer, Abdul. 2009. Sintaksis Bahasa Indonesia (Pendekatan Proses). Jakarta: PT Renika Cipta.

Dardjowidjojo, Soenjono. 1993 Beberapa Aspek Linguistik Indonesia. Jakarta: Djambata

Djajasudharma, T. Fatimah. 2010.Wacana Pemahaman dan Hubungan Antarunsur. Bandung: PT Refika Aditama.

Gustianigsih. 2006. Analisis Wacana Pada Media Cetak Perspektif Linguistik Fungsional Sistemik (LFS) Dan Representasi Semiotik. Dalam http//:www.repository.usu.ac.id.

Halliday, M.A.K. 1994. An Introduction to Functional Grammar. London: Arnold.

Kridalaksana, Harimurti. 2010. Pembentukan Kata dalam Bahasa Indonesia. Jakarta: Kompas Gramedia

Mahsun. 2011. Metode Penelitian Bahasa Tahapan Strategi, Metode, Dan Tekniknya. Jakarta: PT. Raja Grafindo Persada

Muhammad. 2011. Paradigma Kualitatif Penelitian Bahasa. Yogyakarta: Liebe Book Press

Muslich, Masnur. 2010. Tatabentuk Bahasa Indonesia ke Arah Tata Bahasa Deskriptif. Jakarta: Bumi Aksara.

Ramlan. 2001. Sintaksis. Yogyakarta: CV Saryono.

Rohmadi, Muhammad dan I Dewa putu Wijana. 2013. Sosio Linguistik Kajian Teori dan Analisis. Yogyakarta: Pustaka Pelajar

Suhardi. 2013. Pengantar Linguistik Umum. Yogyakarta: AR-RUZ MEDIA

Sumarsono. 2013. Sosiolinguistik. Yogyakarta: Pustaka Pelajar

Syafyahya, Leni dan Aslinda. 2010. Pengantar Sosiso Linguistik. Bandung: PT Rafika Aditama

Syamsudin, Abdul Syukur I M. 1982. Prin- 
sip dan Metode Linguistik Historis. Surabaya:Usaha Nasional

Ullman, Stephen. 2012. Pengantar Semantik. Yogyakarta: Pustaka Pelajar.
Verhaar, J. 2012. A sas-Asas Linguistik Umum. Yogyakarta: Gajah Mada University Press. 